\title{
Pengaruh Pemberian Insentif dan Tunjangan Terhadap Kinerja Karyawan PT. Sri Aneka Karyatama (SAK) Palembang
}

\author{
Benny Usman ${ }^{1}$, Edduar Hendri ${ }^{2}$, Paulia Anggiani ${ }^{3}$ \\ ${ }^{1}$ Fakultas Ekonomi dan Bisnis Universitas PGRI Palembang,benny usman@univpgri-palembang.ac.id \\ ${ }^{2}$ Fakultas Ekonomi dan Bisnis Universitas PGRI Palembang, hendri edduar@yahoo.com \\ ${ }^{3}$ Fakultas Ekonomi dan Bisnis Universitas PGRI Palembang, paulia.angiani@gmail.com
}

\begin{abstract}
ABSTRAK
Penelitian ini bertujuan untuk mengetahui dan menguji ada atau tidaknya pengaruh pemberian insentif dan tunjangan terhadap kinerja karyawan PT. Sri Aneka Karyatama (SAK) Palembang. Teknik pengumpulan data dalam penelitian ini melalui dokumentasi dan penyebaran kuesioner kepada 60 karyawan PT. Sri Aneka Karyatama (SAK) Palembang. Adapun analisis dalam penelitian ini adalah dengan menggunakan program SPSS ( Stasistical Product and Service Solution) versi 23. Teknik uji coba instrument dalam penelitian ini meliputi uji validitas dan uji realiabilitas. Taknik analisis data yaitu uji normalitas, uji multikolonieritas, uji heteroskendastitas, analisis regresi linier berganda, analisis koefisien kolerasi, dan analisis koefisien determinasi $\left(R^{2}\right)$ dan kriteria pengujian hipotesis yaitu uji $t$ dan uji f. Berdasarkan pengelolaan data diperoleh persamaan regresi linier berganda untuk variabel pemberian insentif dan tunjangan terhadap kinerja karyawan adalah $Y=35,347+0,222 X_{1}+0,459 X_{2}$. Berdasarkan uji hipotesis dengan uji t untuk variabel pemberian insentif $\left(X_{1}\right)$ diperoleh signifikan 0,125 $>0,05$ artinya Ho diterima dan Ha ditolak. Dengan demikian secara prsial pemberian insentif tidak berpengaruh signifikan terhadap kinerja karyawan untuk hipotesis $\left(\mathrm{H}_{1}\right)$. Uji hipotesis dengan uji t untuk varibel yunjangan terhadap kinerja karyawan $\left(X_{2}\right)$ diperoleh nilai signifikan $0,028<0,05$ artinya Ho ditolak dan Ha diterima. Dengan demikian secara parsial tunjangan berpengaruh signifikan terhadap kinerja karyawan untuk hipotesis $\left(\mathrm{H}_{2}\right)$. Hasil uji $f$ diperoleh nilai signifikan sebesar $0,002<0,05$ artinya Ho ditolak dan Ha diterima. Dengan demikian secara silmultan pemberian insentif dan tunjangan berpengaruh secara bersama-sama terhadap kinerja karyawan untuk hipotesis ketiga $\left(\mathrm{H}_{3}\right)$
\end{abstract}

Kata Kunci : Pemberian Insentif, Tunjangan, Kinerja Karyawan

\begin{abstract}
This study aims to determine and test the presence or absence of the influence of the provision of incentives and benefits to the performance of employees of PT. Sri Aneka Karyatama (SAK) Palembang. Data collection techniques in this research through documentation and distribution of questionnaires to 60 employees of PT. Sri Aneka Karyatama (SAK) Palembang. The analysis in this research is to use the SPSS program (Statistical Product and Service Solution) version 23. Instrument testing techniques in this study include validity and reliability testing. Data analysis techniques are normality test, multicollinearity test, heteroskendastity test, multiple linear regression analysis, correlation coefficient analysis, and analysis of the coefficient of determination (R2) and hypothesis testing criteria namely $t$ test and $f$ test. Based on the data management, it is obtained the multiple linear regression equation for the variable giving incentives and benefits to employee performance $Y=$ $35,347+0,222 X 1+0,459 X 2$. Based on the hypothesis test with the $t$ test for the variable giving incentives (X1) obtained a significant $0.125>0.05$ means that Ho is accepted and Ha is rejected. Thus partially giving incentives does not significantly influence employee performance for hypothesis (H1). Hypothesis testing with $t$ test for variable benefits on employee performance (X2) obtained a significant value of $0.028<0.05$ meaning $\mathrm{Ho}$ is rejected and Ha is accepted. Thus partially the benefits have a significant effect on employee performance for the hypothesis (H2). The test results $f$ obtained a significant value of $0.002<0.05$ meaning Ho was rejected and Ha was accepted. Thus the simultaneous provision of incentives and benefits jointly affects employee performance for the third hypothesis (H3).
\end{abstract}

Keywords: Giving Incentives, Allowances, Employee Performance 


\section{A. PENDAHULUAN}

Keberhasilan untuk mencapai tujuan perusahaan tergantung pada kualitas dan kuantitas yang dimiliki karyawan dalam menjalankan tugas dan tanggung jawabnya masing-masing. Tujuan perusahaan merupakan peranan penting dalam mewujudkan visi dan misi yang telah ditetapkan perusahaan, tetapi dalam hal tersebut untuk mecapai tujuan perusahaan harus memiliki karyawan yang mempunyai kinerja yang tinggi.

Yani (2012:145) insentif merupakan salah satu penghargaan yang dikaitkan dengan prestasi kerja. Semakin tinggi prestasi kerja, maka semakin tinggi juga insentif yang diberikan. Pemeberian insentif bermanfaat baik bagi perusahaan maupun karyawan. jika insentif yang diterima tidak berkaitan dengan prestasi kerja, tetapi bersifat pribadi maka mereka akan merasakan adanya ketidakadilan dan ketidakadilan ini menyebabkan ketidak puasan yang pada akhirnya dapat mempengaruhi prilaku seperti menurunnya prestasi kerja.

Insentif kelompok merupakan bagi hasil dimana anggota kelompok yang memenuhi syarat tertentu berbagai hasil yang diukur dari kinerja yang diharapkan. Insentif individu adalah insentif yang diberikan kepada karyawan sebagai imbalan atas usaha dan kinerja individual, (Yani 2012:147). Insentif diberikan kepada para pekerja diluar dari gaji utamanya guna mendorong karyawan tersebut agar lebih giat dan semangat lagi dalam meningkatkan kinerja karyawan.

Kadarisman (2014:229) tunjangan adalah komponen imbalan jasa atau penghasilan yang terkait langsung dengan berat ringannya tugas jabatan dan prestasi kerja pegawai atau merupakan indirect compensation. Pada umumnya pemberian tunjangan terkait dengan upaya perusahaan untuk memenuhi kebutuhan pegawainya akan rasa aman ( security need), sebagai bentuk pelayanan kepada pegawai (employee services) serta menunjukkan tanggung jawab sosial perusahaan (company social responsibility) kepada para pegawainya.

Wibowo (2016:7) Kinerja adalah hasil dari sebuah pekerjaan yang mempunyai sebuah hubungan yang kuat dengan tujuan strategis organisasi, kepuasan konsumen dan memberikan kontribusi pada ekonomi. Kinerja dapat diketahui dan diukur jika individu dan sekelompok karyawan telah mempunyai kriteria atau standar keberhasilan tolak ukur yang ditetapkan oleh organisasi. Oleh kerena itu, jika tanpa tujuan dan target yang ditetapkan dalam pengukuran, maka kinerja pada seseorang atau kinerja organisasi tidak mungkin dapat diketahui bila tidak ada tolak ukur keberhasilannya.

\section{B. KAJIAN TEORI \\ 1. Insentif}

Yani (2012:145) insentif adalah salah satu penghargaan yang dikaitkan dengan prestasi kerja. Semakin tinggi prestasi kerja, maka semakin tinggi juga insentif yang diberikan. Pemberian insentif yang diterima tidak dikaitkan dengan prestasi kerja, tetapi bersifat pribadi maka mereka akan merasakan adanya ketidakadilan dapat dipengaruhi perilaku.

Suwatno dan Priansa (2011:234) insentif adalah sesuatu yang merangsang minat untuk bekerja. Kadarisman (2014:198) insentif merupakan penghargaan atau ganjaran yang diberikan untuk memotivasi para pekerja agar produktivitas kerjanya tinggi, sifatnya tidak tetap atau sewaktu-waktu.

Hasibuan (2013:118) insentif adalah tambahan balas jasa yang diberikan kepada karyawan tertentu yang perstasinya diatas prestasi standar. 
Panggabean (2010:89) insentif adalah penghargaan dalam bentuk uang yang diberikan kepada mereka yang dapat bekerja melampaui standar yang telah ditentukan.

\section{Tujangan}

Kadarisman (2014:229) Tunjangan adalah komponen imbalan jasa atau penghasilan yang terkait langsung denngan berat ringannya tugas jabatan dan prestasi kerja pegawai atau merupakan indirect compensation.

Wilson (2012:294) Tunjangan adalah kompensasi keuangan dan bukan keuangan yang diterima karyawan secara tidak langsung untuk berkelanjutan pekerjaan mereka pada perusahaan tempatnya bekerja yang mana tunjangan akan mempengaruhi keputusan karyawan untuk tetap bertahan pada organisasi atau keluar mencari pekerjaan yang memberikan kompensasi yang baik.

Maruli (2016:22) Tunjangan adalah segala pembayaran tambahan oleh perusahaan kepada karyawan yang berupa tunaidan diberikan secara rutin atau periodic kepada karyawan.

Hasibuan (2016:118) tunjangan adalah imbalan tidak langsung yang diberikan kepada seorang karyawann atau sekelompok karyawan sebagai bagian dari keanggotaanya diperusahaan tersebut.

Mangkunegara (2013:86) tunjangan adalah nilai keuangan langsung untuk karyawan yang secara tepat dapat ditentukan, tujuannya untuk memperkecil trun over, meningkatkan modal kerja dan meningkatkan keamanan.

\section{Kinerja Karyawan}

Kasmir (2016:182) kinerja merupakan hasil kerja dan perilaku kerja seseorang dalam satu priode. Kinerja dapat diukur kemampuanya menyelesaikan tugas-tugas dan tanggung jawab yang diberikan kepadanya. Sedangkan menurut Wibowo dalam Oktariansyah (2020:167), kinerja merupakan suatu proses tentang bagaimana pekerjaan berlangsung untuk mencapai hasil kerja.

Mangkunegara (2013:67) kinerja merupakan hasil kerja secara kualitas dan kuantitas yang dicapai oleh seorang karyawan dalam melaksanakan tugasnya sesuai dengan tanggung jawab yang diberikan kepadannya.

Benny Usman (2017:78) kinerja merupakan hasil yang telah dicapai sesorang dalam suatu organisasi sesuai dengan tanggung jawab masing-masing demi mencapai tujuan organisasi tersebut.

Sutrisno Edy (2011:170) kinerja adalah bagaimana seseorang diharapkan dapat berfungsi dan berprilaku sesuai denngan tugas yang telah dibebankan kepadanya. 


\section{Kerangka Berfikir}

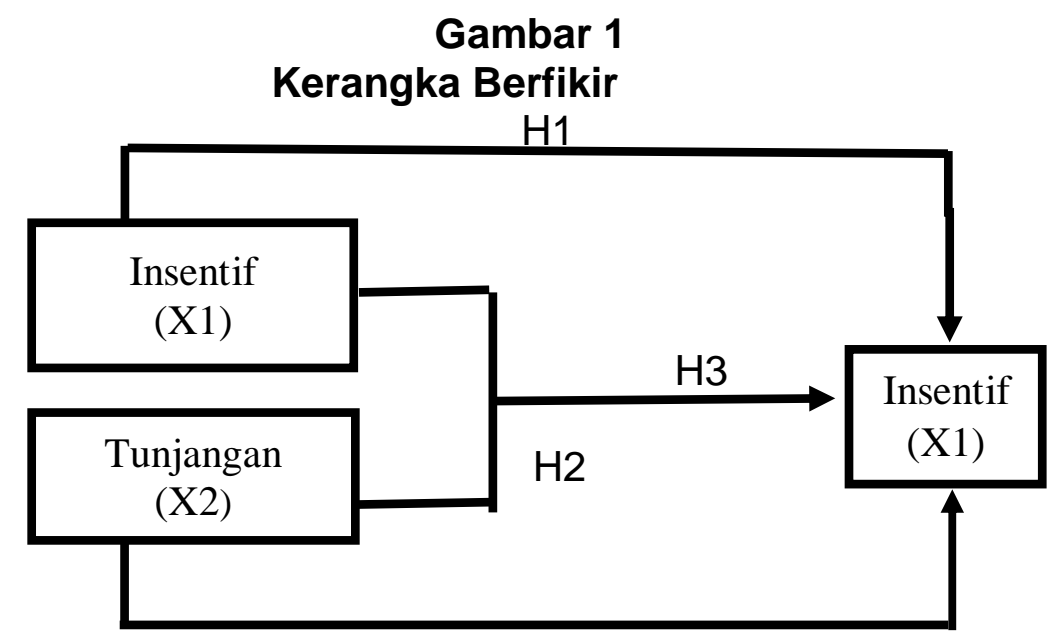

Sugiyono (2018:128) kerangka berfikir adalah model konseptual tentang bagaimana teori berhubungan dengan berbagai faktor yang telah diidentifikasi sebagai masalah yang terpenting. Kerangka berfikir yang baik akan menjelaskan secara teoritis perputaran antara variabel yang akan diteliti. Secara teoritis perlu diketahui atau dijelaskan bahwa hubungan antara variabel independen dan dependen.

\section{Hipotesis Penelitian}

Sugiyono (2018:134) hipotesis penelitian adalah jawaban sementara dari berbagai rumusan masalah penelitian, dimana rumusan masalah penelitian yang dinyatakan dalam bentuk kalimat peryataan. Dikatakan sementara karena jawaban yang diberikan baru didasarkan pada teori yang relevan, belum didasarkan pada fakta-fakta empiris yang diperoleh melalui pengumpulan data.

Hipotesis dapat juga dinyatakan sebagai jawaban yang teoritis terhadap rumusan masalah penelitian, belum jawaban yang empirik. Berdasarkan pengertian hipotesis penelitian diatas, maka hipotesis dalam penelitian ini adalah sebagai berikut:

$\mathrm{H} 1 \quad$ : diduga pemberian insentif berpengaruh positif terhadap kinerja karyawan PT. Sri Aneka Karyatama (SAK) Palembang.

H2 : diduga tunjangan berpengaruh positif terhadap kinerja karyawan PT. Sri Aneka Karyatama (SAK) Palembang.

H3 : diduga pemebrian insentif dan tunjangan berpengaruh positif terhadap kinerja karyawan PT. Sri Aneka Karyatama (SAK) Palembang.

\section{METODE PENELITIAN}

Penelitian ini menggunakan penelitian kuantitatif untuk mengetahui pengaruh antar variabel. Penelitian ini bertujuan untuk mengetahui pengaruh pemberian insentif $(\mathrm{X} 1)$ dan tunjangan $(\mathrm{X} 2)$ terhadap kinerja karyawan $(\mathrm{Y})$.

Metode kuantitaif adalah metode penelitian yang berlandaskan pada filsafat positivisme, digunakan untuk meneliti pada populasi dan sampel tertentu, pengumpulan data menggunkan instrument penelitian, analisis databersifat kuantitatif atau statistik, dengan tujuan untuk menguji hipotesis yang telah ditetapkan. 
Populasi Penelitian ini dilakukan pada karyawan PT. Sri Aneka Karyatama (SAK) Palembang yang berjumlah 150 orang dan Sampel yang menjadi responden dalam penelitian ini disesuaikan menjadi 60 orang dari seluruh total karyawan.

Sujarweni (2019:89) jenis data yang digunakan dalam penelitian ini adalah sebagai berikut :

1. Data Primer

Data primer merupakan data yang diperoleh dari responden melalui kuisioner, kelompok fokus, dan panel, atau juga data hasil wawancara peneliti dengan narasumber. Data yang diperoleh dari data primer ini harus diolah lagi.

2. Data Sekunder

Data sekunder adalah data yang didapat dari catatan, buku, dan majalah berupa laporan keuangan publikasi perusahaaan, laporan pemerintah, artikel, buku-buku sebagai teori, majalah, dan lain sebagainya.

Teknik data yang digunakan dalam pengumpulan data adalah sebagai berikut:

1. Kuesioner

Kuesioner merupakan teknik pengumpulan data dimana partisipan/responden mengisi pertanyaan atau pernyataan kemudian setelah diisi dengan lengkap mengembalikan kepada peneliti.

2. Dokumentasi

Dokumentasi merupakan suatu cara pengumpulan data, bukti dan keterangan yang dapat memberikan informasi serta dapat membantu dalam penelitian.

\section{HASIL PENELITIAN}

a. Uji Asumsi Klasik

1) Uji Normalitas

Priyatno (2014:94) berdasarkan uji normalitas bertujuan menguji apakah data berdistribusi normal atau tidak. Uji normalitas data dilakukan menggunakan uji kolmogrov smirnov untuk menentukan apakah suatu data mengikuti distribusi normal atau tidak dengan melihat nilai signifikannya. Jika signifikannya $>0,05$ maka variabel berdistribusi normal dan sebaliknya jika nilai signifikannya $<0,05$ maka variabel tidak berdistribusi normal.

Tabel Uji Normalitas

One-Sample Kolmogorov-Smirnov Test

\begin{tabular}{|ll|r|r|r|}
\hline & & Insentif & Tunjangan & Kinerja \\
\hline N & & 60 & 60 & 60 \\
Normal Parameters & \\
& Mean & 39.0000 & 35.5500 & 60.7833 \\
& Std. Deviation & 3.94883 & 2.77046 & 4.28672 \\
Most Extreme Differences & Absolute & .110 & .115 & .145 \\
& Positive & .110 & .073 & .145 \\
& Negative & -.083 & -.115 & -.114 \\
Kolmogorov-Smirnov Z & & .855 & .887 & 1.120 \\
Asymp. Sig. (2-tailed) & & .457 & .411 & .163 \\
\hline
\end{tabular}

a. Test distribution is Normal.

b. Calculated from data

Sumber: Data diolah 2020 
Berdasarkan ouput tabel diatas dapat ketahui bahwa nilai signifikan untuk ketiga variabel yaitu pemberian insentif dan tunjangan terhadap kinerja karyawan nilai signifikan lebih besar dari 0,05 maka nilai tresidual berdistribusi normal.

\section{2) Uji Multikolinieritas}

Priyatno (2014:98) ada hubungan linear secara sempurna atau mendekati sempurna antara variabel independen dalam model regresi. Metode untuk menguji adanya multikolieritas ini dapat dilihat dari tolerance value atau variance inflantion factor (VIF). Batasan umum yang digunakan adalah tolerance value lebih dari 0,1 dari nilai VIF kurang dari 10 maka tidak multikolinieritas.

Tabel Uji Multikolineritas Coefficients $^{a}$

\begin{tabular}{|l|r|r|}
\hline \multirow{2}{*}{ Model } & \multicolumn{2}{|c|}{ Collinearity Statistics } \\
\cline { 2 - 3 } & Tolerance & \multicolumn{1}{c|}{ VIF } \\
\hline (Constant) & & \\
Insentif & .777 & 1.287 \\
\hline Tunjangan & .777 & 1.287 \\
\hline
\end{tabular}

Hasil uji multikolinieritas pada tabel diatas dapat diketahui bahwa nilai tolerance lebih besar dari 0,1 dan nilai variance inflaction faktor (VIF) lebih kecil dari 10 variabel.pada variabel insentif $(X 1)$ dan tunjangan $(X 2)$ nilai tolerance 0,777 lebih besar daro 0,1 , sedangkan nilai VIF pada variabel Insentif (X1) dan variabel Tunjangan (X2) sebesar 1,287 lebih kecil dari 10, maka disimpulkan bahwa tidak terjadi multikolinieritas.

\section{3) Uji Heteroskendasitas}

Tabel Uji Heteroskendasitas

\begin{tabular}{|c|c|c|c|c|c|c|}
\hline \multirow{2}{*}{\multicolumn{2}{|c|}{ Model }} & \multicolumn{2}{|c|}{$\begin{array}{c}\text { Unstandardized } \\
\text { Coefficients }\end{array}$} & $\begin{array}{l}\text { Standardized } \\
\text { Coefficients }\end{array}$ & \multirow[b]{2}{*}{$\mathrm{T}$} & \multirow[b]{2}{*}{ Sig. } \\
\hline & & $B$ & Std. Error & Beta & & \\
\hline & (Constant) & 9.488 & 2.896 & & 3.276 & .002 \\
\hline & Insentif & -.037 & .061 & -.087 & -.605 & .548 \\
\hline & Tunjangan & -.133 & .087 & -.220 & -1.521 & .134 \\
\hline
\end{tabular}

Sumber: data diolah, 2020

Berdasarkan tabel diatas menunjukkan bahwa nilai Sig dari uji heteroskedastisitas untuk variabel Insentif sebesar 0,548 atau lebih besar dari 0,05 dan variabel Tunjangan sebesar 0,134 atau lebih besar dari 0,05 maka dapat disimpulkan tidak terjadi heteroskedastisitas

b. Teknik Analisis Data

1) Analisis Regresi Linier berganda 
Tabel Analisis Regresi Linier Berganda

Coefficients $^{a}$

\begin{tabular}{|l|r|r|r|r|r|}
\hline & \multicolumn{2}{|c|}{$\begin{array}{c}\text { Unstandardized } \\
\text { Coefficients }\end{array}$} & $\begin{array}{c}\text { Standardized } \\
\text { Coefficients }\end{array}$ & \multirow{2}{*}{ Sig. } \\
\cline { 2 - 5 } Model & \multicolumn{1}{|c|}{$\mathrm{B}$} & Std. Error & \multicolumn{1}{|c|}{ Beta } & \multicolumn{1}{c|}{$\mathrm{t}$} & \multicolumn{1}{c|}{ Sig. } \\
\hline (Constant) & 35.347 & 6.730 & & 5.252 & .000 \\
Insentif & .222 & .142 & .210 & 1.557 & .125 \\
Tunjangan & .459 & .203 & .305 & 2.262 & .028 \\
\hline
\end{tabular}

Sumber: Data diolah, 2020

Berdasarkan tabel diatas menunjukkan hasil pendugaan koefisien regresi diperoleh nilai regresi untuk Insentif sebesar 0,222 dan nilai koefisien regresi Tunjangan sebesar 0,459 dan konstanta sebesar 35,347 diperoleh persamaan sebagai berikut:

$\mathrm{Y}=\mathrm{a}+\mathrm{b}_{1} \mathrm{X}_{1}+\mathrm{b}_{2} \mathrm{X}_{2}$

$Y=35,347+0,222 X_{1}+0,459 X_{2}$

Konstanta 35,347 artinya jika Insentif (X1) dan Tunjangan (X2) nilainya 0, maka kinerja karyawan $(Y)$ nilainya sebesar 35,347 . Sedangkan koefisien regresi variabel Insentif (X1) sebesar 0,222 artinya jika Insentif mengalam kenaikan satu-satuan, maka kinerja karyawan mengalami peningkatan sebesar 0,222 satuan dengan asumsi variabel independen lainnya bernilai tetap. Dan koefisien Tunjangan (X2) sebesar 0,459 artinya jika Tunjangan mengalami kenaikan satu-satuan, maka kinerja karyawan mengalami peningkatan sebesar 0,459 satuan dengan asumsi variabel independen lainnya bernilai tetap.

\section{2) Koefisien Korelasi}

Tabel Analisis Koefisien Kolerasi

Model Summary

\begin{tabular}{|l|l|l|l|l|}
\hline Model & $R$ & $R$ Square & $\begin{array}{l}\text { Adjusted } \\
\text { Square }\end{array}$ & $\begin{array}{l}\text { Std. Error of } \\
\text { the Estimate }\end{array}$ \\
\hline 1 & $.444^{\mathrm{a}}$ & .197 & .169 & 3.80719 \\
\hline
\end{tabular}

a. Predictors: (constant), Insentif, tunjangan

Sumber: Data diolah, 2020

Berdasarkan tabel diatas dapat dilihat nilai koefisien korelasi ( $R$ ) antara Insentif (X1) dan Tunjangan (X2) dengan Kinerja Karyawan (Y) sebesar 0,444, sementara itu dapat dilihat kriteria pengukurannya sebagai berikut: 
Tabel Interprestasi koefesien Kolerasi Nilai r

\begin{tabular}{|c|c|c|}
\hline No & Interval koefisen & Tingkat Hubungan \\
\hline 1. & $0,80-1,00$ & Sangat Kuat \\
\hline 2. & $0,60-0,79$ & Kuat \\
\hline $\mathbf{3 .}$ & $\mathbf{0 , 4 0 - 0 , 5 9}$ & Sedang \\
\hline 4. & $0,20-0,39$ & Rendah \\
\hline 5. & $0,00-0,19$ & Sangat Rendah \\
\hline
\end{tabular}

Sumber : Sugiyono 2017

Nilai koefisien $(r$ ) yaitu sebesar 0,444 berarti pada nilai 0,40-0,59 hal ini menunjukkan bahwa antara Insentif dan Tunjangan terhadap Kinerja Karyawan adalah sedang.

\section{3) Koefisien Determinasi $\left(\mathbf{R}^{2}\right)$}

Tabel Analisis Koefisien Determinasi $\left(\mathbf{R}^{2}\right)$

Model Summary ${ }^{\mathrm{b}}$

\begin{tabular}{|l|c|r|r|r|}
\hline Model & $\mathrm{R}$ & $\mathrm{R}$ Square & $\begin{array}{c}\text { Adjusted R } \\
\text { Square }\end{array}$ & $\begin{array}{c}\text { Std. Error of } \\
\text { the Estimate }\end{array}$ \\
\hline 1 & $.444^{\mathrm{a}}$ & .197 & .169 & 3.80719 \\
\hline
\end{tabular}

Sumber: data diolah, 2020

Dari tabel diatas diketahui bahwa nilai koefisien determinasi $R$ square $\left(R^{2}\right)$ sebesar 0,197 atau 19,7\% kontribusi Insentif dan Tunjangan terhadap naik turunnya Kinerja karyawan dan sisanya (100\% - 19,7\%) adalah $80,3 \%$ dipengaruhi oleh faktor lain yang tidak ada dalam penelitian ini.

\section{c. Pengujian Hipotesis}

1) Uji Secara Parsial (Uji t)

Tabel Uji t

Coefficients $^{\mathrm{a}}$

\begin{tabular}{|c|c|c|c|c|c|}
\hline \multirow[b]{2}{*}{ Model } & \multicolumn{2}{|c|}{$\begin{array}{l}\text { Unstandardized } \\
\text { Coefficients }\end{array}$} & \multirow{2}{*}{$\begin{array}{c}\begin{array}{c}\text { Standardized } \\
\text { Coefficients }\end{array} \\
\text { Beta }\end{array}$} & \multirow[b]{2}{*}{$\mathrm{t}$} & \multirow[b]{2}{*}{ Sig. } \\
\hline & B & Std. Error & & & \\
\hline (Constant) & 35.347 & 6.730 & & 5.252 & .000 \\
\hline Insentif & .222 & .142 & .210 & 1.557 & .125 \\
\hline Tunjangan & .459 & .203 & .305 & 2.262 & .028 \\
\hline
\end{tabular}

Sumber: data diolah 2020

Berdasarkan tabel diatas dapat dilihat bahwa nilai signifikan untuk variabel Insentif sebesar 0,125 nilai ini lebih besar dari $5 \%(0,125>0,05)$ yang berati $\mathrm{Ho}$ diterima Ha ditolak. Maka dapat disimpulkan Insentif tidak berpengaruh signifikan terhadap Kinerja Karyawan

Untuk variabel nilai signifikan sebesar 0,028 nilai ini lebih kecil dari $5 \%(0,028<0,05)$ yang berarti Ho ditolak dan Ha diterima. Maka dapat disimpulkan bahwa tunjangan berpengaruh signifikan terhadap Kinerja Karyawan. 


\section{2) Uji Secara Simultan (Uji f)}

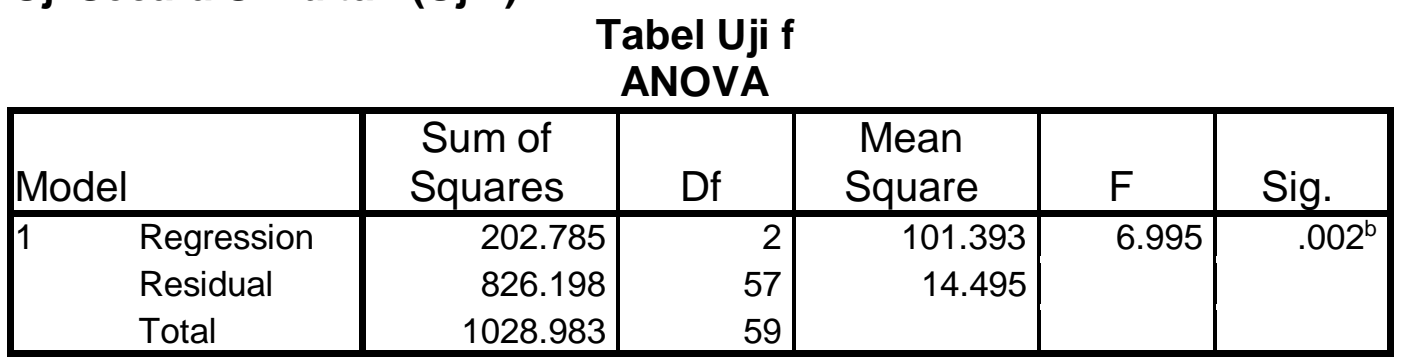

Sumber: data diolah, 2020

Pada tabel diatas, pengujian secara simultan menunjukkan bahwa nilai $\mathrm{F}$ untuk model regresi adalah 6,995 dengan tingkat signifikan 0,002 < 0,05 maka tingkat signifikan model regresi lebih kecil dari taraf nyata.

Hal ini menunjukkan bahwa variabel bebas yaitu Insentif dan Tunjangan secara simultan mempunyai pengaruh yang signifikan terhadap variabel terikat yaitu Kinerja Karyawan.

\section{E. PEMBAHASAN}

1. Pengaruh Pemberian insentif terhadap Kinerja Karyawan PT. Sri Aneka Karyatama (SAK) Palembang.

Dari hasil uji t untuk variabel Insentif (x1) yaitu t hitung $>$ t tabel 1,557 <1,672 Sedangkan sig 0,125 >0,05 nilainya 0,125 maka Ho diterima Ha ditolak, maka dapat disimpulkan bahwa Insentif tidak berpengaruh signifikan terhadap Kinerja Karyawan PT Sri Aneka Karyatama. Hasil penelitian ini tidak sejalan dengan penelitian terdaulu yang dilakukan oleh Azalia (2017) yang berjudul pengaruh pemberian insentif dan reward terhadap kinerja karyawan pada Dapur Solo Kediri secara parsial berpengaruh signifikan terhadap kinerja karyawan pada Dapur Solo Kediri. Hal ini berkaitan dengan Yani (2012:145) insentif adalah salah satu penghargaan yang dikaitkan dengan prestasi kerja. Semakin tinggi prestasi kerja, maka semakin tinggi juga insentif yang diberikan. Pemberian insentif yang diterima tidak dikaitkan dengan prestasi kerja, tetapi bersifat pribadi maka mereka akan merasakan adanya ketidakadilan dapat dipengaruhi perilaku.

\section{Pengaruh Tunjangan terhadap Kinerja Karyawan PT. Sri Aneka Karyatama (SAK) Palembang.}

Dari hasil uji t untuk variabel Insentif (x1) yaitu t hitung $>$ t tabel 2,262 $>0,1672$ Sedangkan sig 0,028 $<0,05$ nilainya 0,028 maka Ho ditolak Ha diterima, maka dapat disimpulkan bahwa Tunjangan berpengaruh signifikan terhadap Kinerja Karyawan PT Sri Aneka Karyatama. Hasil penelitian ini didukung oleh penelitian terdahulu yang dilakukan oleh Nofinawati (2018) yang berjudul pengaruh gaji dan tunjangan terhadap kinerja karyawan Hotel Natama Syariah Padangsidimpuan secara parsial berpengaruh signifikan terhadap kinerja karyawan Hotel Natama Syariah Padangsidimpuan. Hal ini berkaitan dengan Kadarisman (2014:229) Tunjangan adalah komponen imbalan jasa atau penghasilan yang terkait langsung denngan berat ringannya tugas jabatan dan prestasi kerja pegawai atau merupakan indirect compensation. 


\section{Pengaruh Pemberian Insentif dan Tunjangan terhadap Kinerja Karyawan PT. Sri Aneka Karyatama (SAK) Palembang.}

Dari hasil Uji $F$ diatas diperoleh $F$ hitung sebesar 6,995 sementara untuk $F$ tabel dengan signifikan $\mathrm{a}=0,05$ dan $\mathrm{df}=2$ maka didapat $\mathrm{F}$ tabel $=3,156$. Nilai $\mathrm{F}$ hitung lebih besar dari $F$ tabel $(6,995>3,156)$ dan nilai signifikan sebesar 0,02 dapat disimpulkan model regresi ini dapat digunakan karena tingkat signifikan lebih kecil dari 0,05 ( 0,02 < 0,05), bahwa hasilnya Ho ditolak dan Ha diterima sehingga dapat dikatakan bahwa ada hubungan yang signifikan antara variabel Insentif dan Tunjangan secara simultan atau bersama-sama terhadap Kinerja Karyawan PT Sri Aneka Karyatama. Hasil penelitian ini mendukung hasil penelitian terdahulu yang dilakukan oleh Huda (2015) yang berjudul pengaruh pemberian insentif dan tunjangan teradap kinerja karyawan PT. BPRS Sukowati Sragen berpengruh secara simultan bersama-sama terhadap kinerja karyawan pada PT. BPRS Sukowati Sragen. Hal ini berkaitan dengan pendapat Wibowo (2016:7) Kinerja adalah hasil dari sebuah pekerjaan yang mempunyai sebuah hubungan yang kuat dengan tujuan strategis organisasi, kepuasan konsumen dan memberikan kontribusi pada ekonomi.

\section{F. KESIMPULAN DAN SARAN}

1. Kesimpulan

Penelitian ini bertujuan untuk mengetahui adanya hubungan antara Insentif dan Tunjangan terhadap Kinerja Kayawan pada PT. Sri Aneka Karyatama. Berdasarkan hasil pengujian Hipotesis yang dilakukan pada bab 4 dapat dilihat kesimpulan berikut ini:

a) Dari hasil pengujian hipotesis Uji t secara parsial antara variabel Insentif (X1) terhadap Kinerja Karyawan (Y) diperoleh nilai Signifikan 0,125 lebih dari 0,05 maka dapat disimpulkan bahwa secara parsial tidak berpengaruh signifikan antara Insentif terhap Kinerja Karyawan PT. Sri Aneka Karyatama (SAK) Palembang.

b) Dari hasil pengujian hipotesis Uji t secara parsial antara variabel Tunjangan (X2) terhadap Kinerja Karyawan $(Y)$ diperoleh nilai Signifikan 0,028 lebih dari 0,05 maka dapat disimpulkan bahwa secara parsial berpengaruh signifikan antara Tunjangan terhadap Kinerja Karyawan PT. Sri Aneka Karyatama (SAK) Palembang.

c) Dari hasil uji F secara simultan antara variabel Insentif dan Tunjangan terhadap Kinerja Karyawan diperoleh nilai $F$ hitung sebesar 6,695 dan nilai signifikan 0,02 kurang dari 0,05. Maka dapat disimpulkam bahwa secara simultan ada pengaruh signifikan antara variabel Insentif dan Tunjangan terhadap Kinerja Karyawan PT Sri Aneka Karyatama (SAK) Palembang.

\section{Saran}

Sehubungan dengan hasil yang telah dicapai dalam penelitian ini, ada beberapa saran yang ditemukan oleh penelitian yaitu, sebagai berikut:

a) Mengingat berdasarkan penelitian ini, diperoleh hasil adanya pengaruh dan hubungan yang cukup antara pemberian inisentif dan tunjangan terhadap kinerja karyawan di PT. Sri Aneka Karyatama (SAK) Palembang, maka peneliti menyarankan untuk mempertahankan masalah kinerja karyawan.

b) PT. Sri Aneka Karyatama (SAK) Palembang sebaiknya mampu untuk mempertahankan kinerja karyawan dalam menjalankan suatu organisasi dalam 
perusahaan, dan dapat mempertahankan kinerja karyawan dan meningkatkan pemberian insentif dan tunjangan yang lebi baik.

c) Mengingat berdasarkan penelitian ini, diperoleh hasil adanya pengaruh dan hubungan yang cukup antara pemberian insentif dan tunjangan terhadap kinerja karyawan PT. Sri Aneka Karyatama (SAK) Palembang. Sebaiknya peneliti menyarankan agar karyawan dapat lebih aktif dalam meningkatkan kinerja karyawan.

\section{DAFTAR PUSTAKA}

Bangun, Wilson.(2012) Manajemen Sumber Daya Manusi. Jakarta: Erlangga

Hasibuan, Malayu S.P. (2013). Manajemen Sumber Daya Manusia. Edisi Revisi. Jakarta: PT. Bumi Aksara.

Hasibuan, Malayu S.P. (2016). Manajemen Sumber Daya Manusia. Edisi Revisi. Jakarta: PT.Bumi Aksara.

Kadarisman. (2014). Manajemen Kompensasi . Jakarta. PT Raja Grafindo Persada.

Kasmir. (2016). Manajemen Sumber Daya Manusia ( Teori dan Praktik). Jakarta: PT Raja Grafindo Persada.

Mangkunegara, Anwar. Prabu. (2013). Manajemen Sumber Daya Manusia . Jakarta :PT Raja Grafindo Persada.

Oktariansyah. (2020). Pengaruh Karakteristik Individual dan Lingkungan Kerja Terhadap Kinerja Pegawai Kantor Dinas Transmigrasi Kabupaten Banyuasin. Jurnal Media Wahana Ekonomika. Vol 17 No 2. Juli 2020. Halaman 167

Panggabean, Mutiara S. (2010) Manajemen Sumber Daya Manusia. Bogor: Ghalia Indonesia.

Priyatno, Dwi. (2014). SPSS 22 Pengolahan Data Terpraktis. yogyakarta: Andi Offset.

Sahat Maruli. (2016). Analisis Pengaruh Gaji, Tunjangan dan Fasilitas Kerja Terhadap Kinerja karyawan Pabrik Roti Universal (Bayu Bagus) Baron Nganjuk. Skripsi. UN PGRI Kediri.

Sugiyono. (2018). Metode Penelitian Manajemen. Bandung: Alfabeta .

Sujarweni, V. Wiratna. (2019). Metode Penelitian Bisnis \& Ekonomi. Yogyakarta: Pustaka Baru Press.

Sutrisno, Edy. (2011). Budaya Organisasi. Jakarta: Kencana Prenada Media Grup.

Suwatno dan Priansa. (2011). Manajemen SDM Dalam Organisasi Publik dan Bisnis . Bandung: Alfabeta . 
Suwatno dan Priansa. (2016). Manajemen SDM dalam Organisasi Publik dan Bisnis . Bandung: Alfabeta.

Usman, Benny. (2017). Pengaruh Promosi Jabatan Terhadap Kinerja Karyawan Pada CV Sedulur Palembang. Jurnal Ekonomi, Manajemen, Bisnis, Auditing, dan Akuntansi. Vol 2 No 2. Halaman 84

Wibowo. (2014). Manajemen Kinerja Edisi ke-4. Jakarta:PT Raja Grafindo Persada.

Wibowo. (2016). Manajemen Kinerja edisi ke lima. cetakan ke-11. Jakarta.:PT Raja Grafindo Persada.

Yani, Muhammad. (2012). Manajemen Sember Daya Manusia. Jakarta. Mitra Wacana Media. 